\title{
Influence of contact effect on the performance of microcrystalline silicon thin-film transistors
}

Kah-Yoong Chan, Eerke Bunte, Helmut Stiebig, and Dietmar Knipp

Citation: Appl. Phys. Lett. 89, 203509 (2006);

View online: https://doi.org/10.1063/1.2390634

View Table of Contents: http://aip.scitation.org/toc/apl/89/20

Published by the American Institute of Physics

\section{Articles you may be interested in}

High-mobility field-effect transistors based on transition metal dichalcogenides

Applied Physics Letters 84, 3301 (2004); 10.1063/1.1723695

The enhanced low resistance contacts and boosted mobility in two-dimensional p-type WSe 2 transistors through $\mathrm{Ar}^{+}$ion-beam generated surface defects

AIP Advances 6, 105307 (2016); 10.1063/1.4966049

Air stable $\mathrm{n}$-doping of $\mathrm{WSe}_{2}$ by silicon nitride thin films with tunable fixed charge density

APL Materials 2, 092504 (2014); 10.1063/1.4891824

WSe 2 field effect transistors with enhanced ambipolar characteristics

Applied Physics Letters 103, 103501 (2013); 10.1063/1.4820408

Thickness dependence of nanofilm elastic modulus

Applied Physics Letters 94, 152111 (2009); 10.1063/1.3120763

High gain, low noise, fully complementary logic inverter based on bi-layer WSe 2 field effect transistors

Applied Physics Letters 105, 083511 (2014); 10.1063/1.4894426

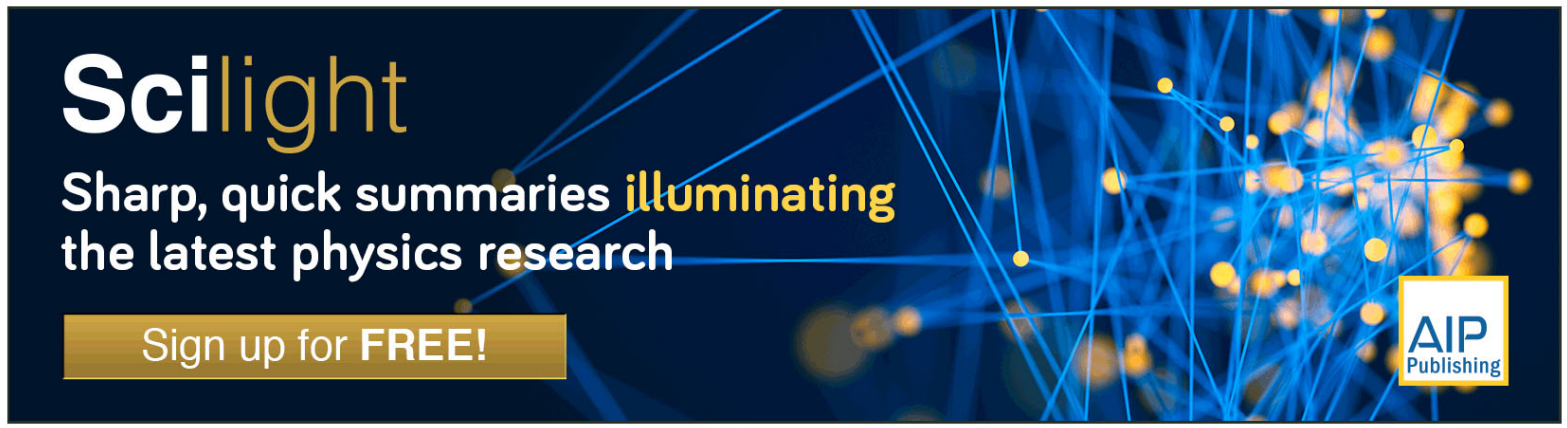




\title{
Influence of contact effect on the performance of microcrystalline silicon thin-film transistors
}

\author{
Kah-Yoong Chan ${ }^{\mathrm{a})}$ \\ School of Engineering and Science, International University Bremen, 28759 Bremen, Germany \\ and Institute of Photovoltaics, Research Center Jülich, 52425 Jülich, Germany \\ Eerke Bunte and Helmut Stiebig \\ Institute of Photovoltaics, Research Center Jülich, 52425 Jülich, Germany \\ Dietmar Knipp \\ School of Engineering and Science, International University Bremen, 28759 Bremen, Germany
}

(Received 18 July 2006; accepted 10 October 2006)

\begin{abstract}
Microcrystalline silicon thin-film transistors were prepared by plasma-enhanced chemical vapor deposition at substrate temperatures below $200{ }^{\circ} \mathrm{C}$. The transistors exhibit electron mobilities of $38 \mathrm{~cm}^{2} / \mathrm{V} \mathrm{s}$, threshold voltages in the range of $2 \mathrm{~V}$, and subthreshold slopes of $0.3 \mathrm{~V} /$ decade. Despite the realization of transistors with high carrier mobility, contact effects limit the performance of the transistors. The influence of the drain and source contacts on device parameters including the mobility, the threshold voltage, and the subthreshold slope will be discussed in detail. (c) 2006 American Institute of Physics. [DOI: 10.1063/1.2390634]
\end{abstract}

With the advance of flat-panel display technologies thinfilm transistors (TFTs) based on amorphous silicon ( $a$ $-\mathrm{Si}: \mathrm{H})$ have established themselves as an inexpensive and reliable technology for display back panels. The electron mobility of $a$-Si:H TFTs allows for operation of liquid crystal flat-panel displays at video rate. However, the performance of $a$-Si:H TFTs does not enable the operation of organic light-emitting diode (OLED) displays or radio-frequency identification tags. In order to provide stable operation of large-area OLED displays at video rate, the carrier mobility has to be in the range of $5 \mathrm{~cm}^{2} / \mathrm{V} \mathrm{s}$ or higher. ${ }^{1}$ Furthermore, the threshold voltage of the TFTs has to be stable during device operation. As the threshold voltage of $a$-Si:H TFTs is not stable due to the creation of electronic defects during operation, ${ }^{2} a$-Si:H TFTs are not suitable for such applications. So far only polycrystalline silicon (poly-Si) TFTs provide sufficiently high carrier mobilities and stable threshold voltages.

An alternative material that exhibits high carrier mobilities is hydrogenated microcrystalline silicon $(\mu \mathrm{c}-\mathrm{Si}: \mathrm{H})$. The material mainly consists of amorphous and crystalline phase. $\mu \mathrm{c}-\mathrm{Si}: \mathrm{H}$ TFTs combine two worlds of low temperatures processing with the performance of poly-Si TFTs. So far device mobilities of $>40 \mathrm{~cm}^{2} / \mathrm{V} \mathrm{s}$ were reported by Cheng and Wagner, ${ }^{3}$ Lee et al., ${ }^{4}$ and Saboundji et al. ${ }^{5}$ Despite the realization of transistors with high carrier mobility, the electronic transport in such TFTs is not fully understood. In particular, the influence of the drain and source contacts on the device performance is still under investigation. In the following, $\mu \mathrm{c}-\mathrm{Si}: \mathrm{H}$ TFTs with channel lengths ranging from 2 to $200 \mu \mathrm{m}$ were characterized and analyzed. The short channel TFTs with channel length below $10 \mu \mathrm{m}$ enable a detailed discussion of the influence of contacts on the device properties.

A schematic cross section of the realized TFT is shown in Fig. 1. Top-gate staggered TFT structures were used in this study to take full advantage of the high crystalline volume

${ }^{a)}$ Electronic mail: k.y.chan@fz-juelich.de fraction of bulk $\mu \mathrm{c}-\mathrm{Si}: \mathrm{H}^{6}{ }^{6}$ The drain and source contacts of the TFTs were realized by chromium with $30 \mathrm{~nm}$ thickness. Afterwards, a highly doped $n$-type $\mu \mathrm{c}-\mathrm{Si}: \mathrm{H}$ film is deposited by plasma-enhanced chemical vapor deposition (PECVD) to form Ohmic contacts between the drain and source electrodes and the channel material. An intrinsic (i) $\mu \mathrm{c}-\mathrm{Si}: \mathrm{H}$ layer with $100 \mathrm{~nm}$ thickness, which acts as channel, and gate dielectric of $300 \mathrm{~nm}$, were prepared by PECVD. The dielectric was realized by silicon dioxide $\left(\mathrm{SiO}_{2}\right)$. $\mathrm{SiO}_{2}$ was used as a gate dielectric to minimize the defect density at the channel/dielectric interface. ${ }^{7,8}$

The microcrystalline $n$ and $i$ layers were prepared at radio frequencies of $13.56 \mathrm{MHz}$ and substrate temperatures of 190 and $160{ }^{\circ} \mathrm{C}$, respectively. The microcrystalline material was grown in the high pressure and high power regime, which facilitates the deposition at high deposition rates. ${ }^{9,10}$ The deposition pressure of the $i$ layer was $1330 \mathrm{~Pa}$ and the power density was $0.3 \mathrm{~W} / \mathrm{cm}^{2}$. For these parameters a deposition rate of $0.3 \mathrm{~nm} / \mathrm{s}$ was achieved. The $i$ layer exhibits a dark conductivity in the order of $10^{-6} \mathrm{~S} / \mathrm{cm}$ and a crystalline volume fraction of $55 \%$. The $\mathrm{SiO}_{2}$ was prepared at $150{ }^{\circ} \mathrm{C}$. To clean and hydrogenate the $i$-layer surface the samples were subjected to a hydrofluoric acid dip prior to the deposition of $\mathrm{SiO}_{2}$. Finally, the gate electrode is formed by an aluminum film. The devices were fabricated on Corning 1737 glass. Transistors with channel length and width rang-

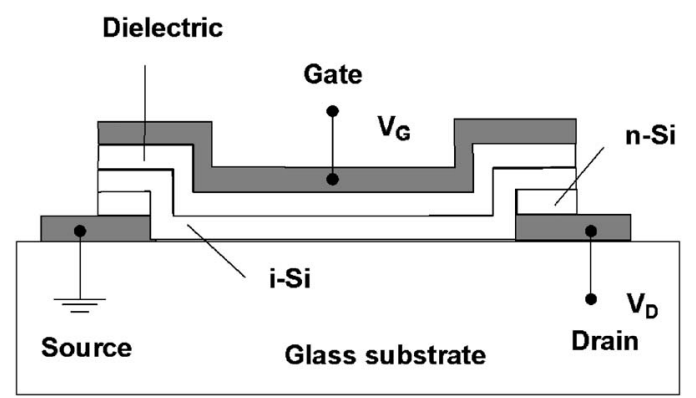

FIG. 1. Schematic cross section of a top-gate staggered $\mu \mathrm{c}-\mathrm{Si}: \mathrm{H}$ TFT. The transistor was fabricated by using a two-mask photolithographic process. 


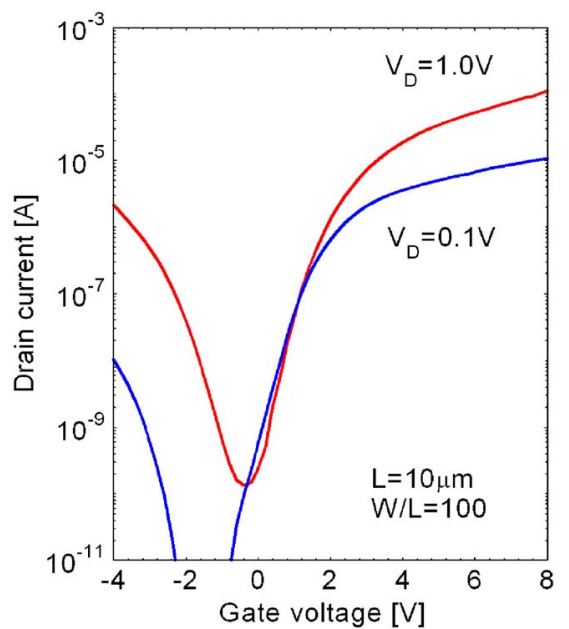

FIG. 2. (Color online) Transfer characteristics of a $\mu \mathrm{c}-\mathrm{Si}: \mathrm{H}$ TFT (annealed at $150{ }^{\circ} \mathrm{C}$ for $30 \mathrm{~min}$ ) with $W=1000 \mu \mathrm{m}$ and $L=10 \mu \mathrm{m}$. The transfer curves were measured for $V_{D}=0.1$ and $1 \mathrm{~V}$.

ing from 2 to $200 \mu \mathrm{m}$ and from 200 to $1000 \mu \mathrm{m}$ were fabricated, respectively. To allow for the fast evaluation of the materials and the device properties, a simple two-mask photolithography process was developed.

In order to improve the device behavior all transistors were annealed at an elevated temperature of $150{ }^{\circ} \mathrm{C}$ for 30 min under ambient conditions. The annealing temperature was selected to be close to the deposition temperature of $i$ layer to avoid the degradation of the device and the effusion of hydrogen out of the film. ${ }^{11}$ A detailed discussion of the influence of thermal annealing on the device characteristics is given elsewhere. ${ }^{12}$

The device characterization was performed at room temperature under dark conditions. In this letter, typical device data of TFTs after several measurements are presented, since the initial measurement significantly deviates from their stable device performance.

The device mobility $\mu$ of the transistors was extracted using following equation for the drain current $I_{D}$ in linear region from the measured transfer characteristics:

$$
I_{D}=\mu C_{G} \frac{W}{L}\left(V_{G}-V_{T}-\frac{V_{D}}{2}\right) V_{D}
$$

where $W$ and $L$ is the channel width and length of the TFT, respectively, $C_{G}$ is the gate capacitance per unit area, $V_{G}, V_{T}$, and $V_{D}$ are the gate voltage, threshold voltage, and drain voltage, respectively. A device mobility of $13 \mathrm{~cm}^{2} / \mathrm{V} \mathrm{s}$ was extracted from the transfer characteristics in Fig. 2. The on/ off ratio of the TFT for low drain voltages is larger than $10^{6}$. The gate leakage current of the transistor is four orders of magnitude lower than the corresponding drain current at high gate voltages (not shown).

Measurements of devices with different device geometries were performed. The extracted device mobility as a function of the channel length is shown in Fig. 3. The obtained values strongly depend on the channel length. For long channel devices $(L=200 \mu \mathrm{m})$ a device mobility of $35 \mathrm{~cm}^{2} / \mathrm{V} \mathrm{s}$ is extracted, whereas for short channel devices $(L=2 \mu \mathrm{m})$ the determined value is reduced to $7 \mathrm{~cm}^{2} / \mathrm{V} \mathrm{s}$ for $V_{D}=0.1 \mathrm{~V}$. Similar data were published by other group for the channel length dependence of the device mobility of $\mu \mathrm{c}-\mathrm{Si}: \mathrm{H}$ TFTs. ${ }^{4}$

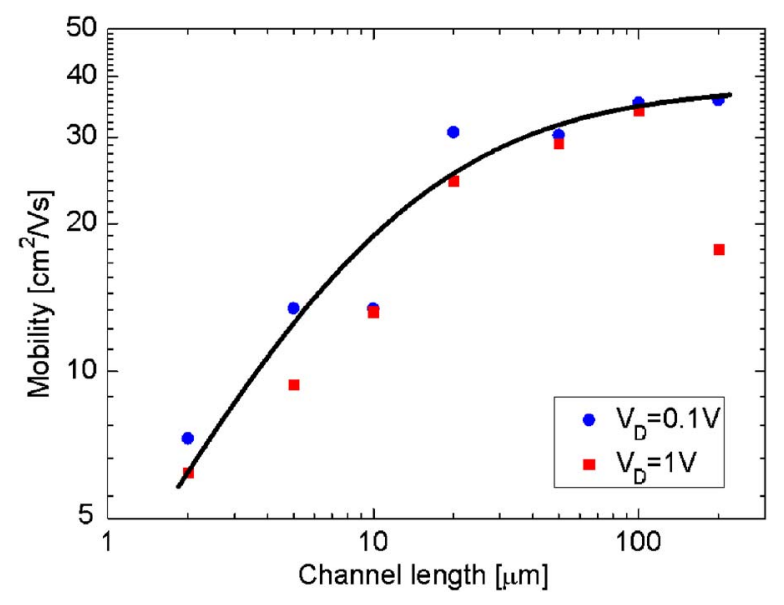

FIG. 3. (Color online) Measured device mobility as a function of channel length for annealed $\mu \mathrm{c}-\mathrm{Si}: \mathrm{H}$ TFTs.

The reduction of the device mobility for short channel transistors can be explained by the influence of the drain and source contacts on the potential distribution across the channel. The nonideal contact behavior causes a voltage drop at the drain and source contacts, which leads to a reduction in the channel potential. In the following it is assumed that the contacts can be described by Ohmic contacts, so that the drain voltage in Eq. (1) can be replaced by $V_{D}-I_{D} R_{C}$, where $V_{D}-I_{D} R_{C}=V_{D 0}$ represents the voltage drop across the channel. $R_{C}$ is the resistance of the drain and source contacts. The influence of the contacts on the device behavior is more pronounced for short channel devices, since the drain current is proportional to $V_{D 0} / L$.

Considering the nonideal contact behavior, the following expression for the mobility can be derived:

$$
\mu \approx \mu_{0} \frac{L}{L+\mu_{0} W C_{G} R_{C}\left(V_{G}-V_{T}\right)},
$$

where $\mu_{0}$ is the electron mobility of the microcrystalline channel material and $\mu$ is the device mobility extracted from the measured transistors, which is affected by the influence of the drain and source contacts. Equation (2) was employed to fit the experimental data in Fig. 3. We extracted a $\mu_{0}$ of $38 \mathrm{~cm}^{2} / \mathrm{V} \mathrm{s}$ and a $R_{C}$ of $5.6 \mathrm{k} \Omega$. A good agreement between the experimental data and the fit was achieved, nearly independent from $V_{D}\left(0.1 \mathrm{~V}<V_{D}<1 \mathrm{~V}\right)$. Furthermore the transmission line model ${ }^{13}$ was used to extract the contact resistance of the transistors. Both methods exhibit very similar values for the contact resistance.

The device threshold voltage $V_{T}$ extracted from Eq. (1) as a function of the channel length is shown in Fig. 4(a). The data were extracted from the transfer curves measured at $V_{D}=0.1$ and $1 \mathrm{~V}$. The device threshold voltage apparently increases for longer channel transistors. The channel length dependent device threshold voltage can again be explained by the influence of the drain and source contacts on the threshold voltage. Taking the influence of the contact effects into account the following expression for the device threshold voltage which is the extrapolation of the drain current to $I_{D}=0$ can be derived from Eq. (1) by substituting $V_{D}-I_{D} R_{C}$ for $V_{D}$ : 

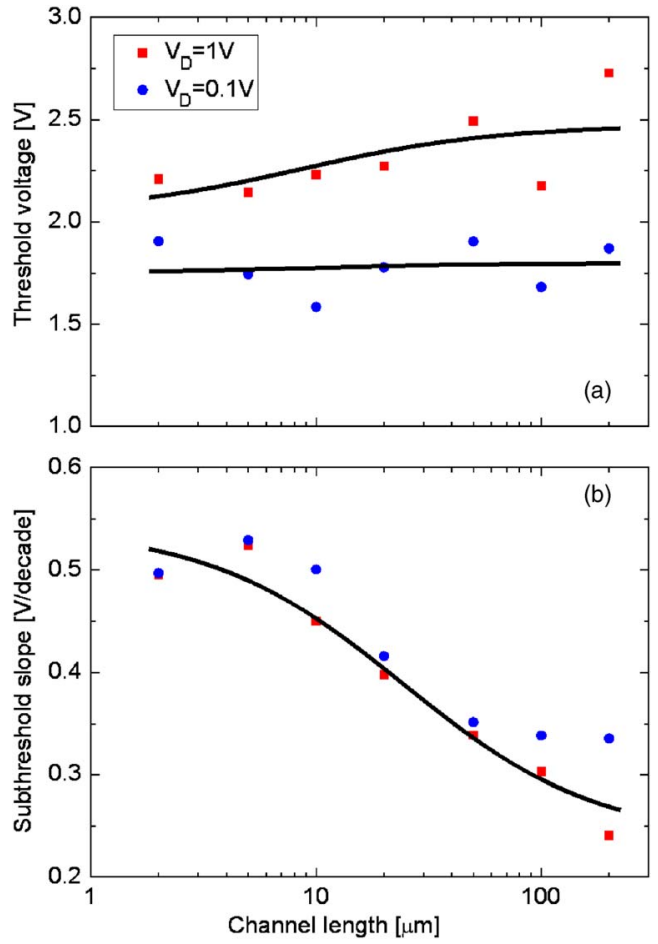

FIG. 4. (Color online) Measured device threshold voltage (a) and subthreshold slope (b) for annealed $\mu \mathrm{c}-\mathrm{Si}: \mathrm{H}$ TFTs as a function of channel length.

$$
V_{T}=V_{T 0}-\frac{I_{D} R_{C}}{2},
$$

where $V_{T 0}$ is the threshold voltage of the $\mu \mathrm{c}-\mathrm{Si}: \mathrm{H}$ TFT, which is not affected by the influence of the contacts. The $V_{T}$ is close to $V_{T 0}$ for long channel transistors. For short channel devices the contact effects are more pronounced, which leads to a reduction of the $V_{T}$. Equation (3) was used to fit the extracted device threshold voltages in Fig. 4(a). A good agreement between the experimental data and fit was achieved, which underlines that the channel length dependence of the device threshold voltage can also be explained by the drain and source contact effects. From the fit of the device threshold voltage, we extracted a $V_{T 0}$ value of $2.5 \mathrm{~V}$. The extracted $R_{C}$ is identical with the value extracted from the fit of the channel length dependence of the device mobility.

The device threshold voltage of the transistors is closely related to the subthreshold slope. The device subthreshold slope $S$ as a function of the channel length is shown in Fig. 4(b) for $V_{D}=0.1$ and $1 \mathrm{~V}$. As expected the subthreshold slope is nearly independent of the drain voltage. Investigating the channel length dependence, a decrease of the device subthreshold slope with increasing channel length is observed. The device subthreshold slope is determined by

$$
S=\frac{\partial V_{G}}{\partial\left(\log \left(I_{D \text { sub }}\right)\right)},
$$

where $I_{D \text { sub }}$ is the drain current in the subthreshold region, which is described by following relationship: ${ }^{14}$

$$
I_{D \text { sub }} \propto \frac{W}{L} \mu \exp \left(\frac{C_{G} V_{G}}{q N_{T} d_{S} k_{B} T}\right),
$$

where $q, N_{T}, d_{S}, k_{B}$, and $T$ is the electron charge, the defect density in the $\mu \mathrm{c}-\mathrm{Si}: \mathrm{H}$, the $\mu \mathrm{c}-\mathrm{Si}: \mathrm{H}$ channel layer thickness, the Boltzmann constant, and the temperature, respectively. The determined defect density $\left(3.5 \times 10^{16} \mathrm{~cm}^{-3}\right.$ is in the range of the values obtained from the electron spin resonance and detailed device analysis. ${ }^{15}$ This underlines that Eq. (5) can be applied to describe the subthreshold current of the $\mu \mathrm{c}-\mathrm{Si}: \mathrm{H}$ TFTs. The device mobility was used in Eq. (5) to account for the contact effects on the subthreshold current. By substituting Eq. (2) into Eq. (5), the device subthreshold slope

$$
S=S_{0} \frac{L+W \mu_{0} C_{G} R_{C}\left(V_{G}-V_{T}\right)}{L+W \mu_{0} R_{C}\left[C_{G}\left(V_{G}-V_{T}\right)-q N_{T} d_{s} k_{B} T\right]},
$$

where $S_{0}$ is the subthreshold slope of the $\mu \mathrm{c}-\mathrm{Si}: \mathrm{H}$ TFT, which is not affected by the influence of the contacts, while $S$ is influenced by the contacts. Equation (6) shows that the device subthreshold slope increases for short channel devices, which is consistent with the experimental data in Fig. 4(b).

The realized $\mu \mathrm{c}-\mathrm{Si}: \mathrm{H}$ TFTs exhibit electron mobilities of $38 \mathrm{~cm}^{2} / \mathrm{V} \mathrm{s}$, threshold voltages in the range of $2 \mathrm{~V}$, and subthreshold slopes of $0.3 \mathrm{~V} /$ decade. The experimental results reveal that the channel length has a distinct influence on extracted device parameters such as mobility, threshold voltage, and subthreshold slope. The device mobility decreases for short channel transistors. A detailed analysis reveals that the reduced device mobility can be attributed to the influence of the drain and source contacts. The device threshold voltage decreases and the subthreshold slope increases with decreasing channel length, which is attributed to the similar contact effects.

The authors like to acknowledge S. Bunte (IBN-PT) for preparation of the PECVD $\mathrm{SiO}_{2}$, P. Foucart, M. Hülsbeck, J. Kirchhoff, S. Michel, and R. Schmitz for technical assistances, and R. Carius, M. v. d. Donker, D. Hrunski, and B. Rech for helpful discussions.

\footnotetext{
${ }^{1}$ M. Stewart, R. S. Howell, L. Pires, and M. K. Hatalis, IEEE Trans. Electron Devices 48846 (2001).

${ }^{2}$ T. Tsukada, in Technology and Applications of Amorphous Silicon, edited by R. A. Street, Springer Series in Material Science, Vol. 37 (SpringerVerlag, Berlin, 2000).

${ }^{3}$ I.-C. Cheng and S. Wagner, Appl. Phys. Lett. 80, 440 (2002).

${ }^{4}$ C.-H. Lee, A. Sazonov, and A. Nathan, Appl. Phys. Lett. 86, 222106 (2005).

${ }^{5}$ A. Saboundji, N. Coulon, A. Gorin, H. Lhermite, T. Mohammed-Brahim, M. Fonrodona, J. Bertomeu, and J. Andreu, Thin Solid Films 487, 227 (2005).

${ }^{6}$ H. Shirai, T. Arai, and T. Nakamura, Appl. Surf. Sci. 113/114, 111 (1997).

${ }^{7}$ Y. Ma, T. Yasuda, and G. Lucovsky, J. Vac. Sci. Technol. A 11, 952 (1993).

${ }^{8}$ S. W. Hsieh, C. Y. Chang, and S. C. Hsu, J. Appl. Phys. 74, 2638 (1993).

${ }^{9}$ L. Guo, M. Kondo, M. Fukawa, K. Saitoh, and A. Matsuda, Jpn. J. Appl. Phys., Part 2 37, L1116 (1998).

${ }^{10}$ B. Rech, T. Roschek, T. Repmann, J. Müller, R. Schmitz, and W. Appenzeller, Thin Solid Films 427, 161 (2003).

${ }^{11}$ W. Beyer and U. Zastrow, J. Non-Cryst. Solids 266-269, 206 (2000).

${ }^{12}$ K.-Y. Chan, E. Bunte, D. Knipp, and H. Stiebig, J. Appl. Phys. (submitted).

${ }^{13}$ S. Luan and G. W. Neudeck, J. Appl. Phys. 72, 766 (1992).

${ }^{14}$ D. W. Greve, Field Effect Devices and Applications: Devices for Portable, Low-Power, and Imaging Systems, 1st ed. (Prentice-Hall, Englewood Cliffs, NJ, 1998), Chap. 7, p. 287.

${ }^{15}$ T. Brammer and H. Stiebig, J. Appl. Phys. 94, 1035 (2003).
} 